\title{
Tourist Expectation and Tourist Experience in Cultural Tourism
}

\author{
Orawan Boonpat \\ Khon Kaen University, Khon Kaen, Thailand \\ Chiang Rai Rajabhat University, Chiang Rai, Thailand \\ Noppamash Suvachart \\ Khon Kaen University, Khon Kaen, Thailand
}

\begin{abstract}
Chiang Rai is one of the most famous destinations in Thailand due to its rich tourism resources especially with many cultural resources and well-organized and developed tourism infrastructure. As a consequence, Chiang Rai has targeted to promote and develop cultural tourism in order to attract more foreign tourists to visit and satisfy their needs and expectations, which is seen as one of the most important aspects in the current tourism development strategies in Chiang Rai. Therefore, the main purpose of this study is to compare the gap between pre- and post-experience of foreign tourists who visited Chiang Rai towards their expectation and experience on: (1) arts and crafts; (2) life style of local people; (3) local food; (4) festivals and local traditions; (5) ethnic/indigenous life style and culture; and (6) cultural heritage. The quantitative approach has been chosen to conduct the study by using a questionnaire with 400 foreign tourists and One-way ANOVA was the statistic used for gap analysis between tourist expectation and experience. The data collection included the analysis of government documents and the relevant literature. The finding of the study illustrated that cultural tourism plays an important role in tourism development in Chiang Rai and the gap between pre- and post-experience of tourists. However, in order to minimize the gap between pre- and post-experience of tourists and maximize their expectation and satisfaction, both government and private sectors should have an in-depth understanding towards the management of cultural tourism. The tourist needs more quality cultural products and foreign language skills from staff and local people.
\end{abstract}

Keywords: tourist expectation, tourist experience, cultural tourism

\section{Introduction}

Recently, cultural tourism has been targeted as the main approach for tourism development in most regions worldwide, particularly the old cities or towns. This is due to its rich cultural resources and heritage such as the unique ways of life, food, events and festivals, culture and tradition, language, costume, ethnic or indigenous culture, and so forth. According to Figini and Vici (2012), cultural tourism is considered as the approach that is able to minimize the impact of tourism but will generate a local awareness to protect and conserve their local heritage. However, nowadays, it seems that conventional or mass tourism is still the main form of tourism which mostly focuses on the number of tourists rather than on quality. It might be argued that this form of tour is still popular due to business reason of travel companies and the size of tourist demand. Most of conventional

Orawan Boonpat, Ph.D. candidate in Tourism and Hospitality Innovation Management, Faculty of Management Science, Khon Kaen University; lecturer, School of Tourism, Chiang Rai Rajabhat University. Email: oboonpat@hotmail.com.

Noppamash Suvachart, DBA, associate professor, Faculty of Management Science, Khon Kaen University. 
tours are in the form of ready-made tour which packed together food services, accommodation, guide services, and transport services in designed time period such as city tour, sightseeing tour, and the like. This form of tour has resulted in less opportunity for tourists to earn in-depth experience and understand the story and unique aspect of the destination (and tourism products such as cultural uniqueness). One of the best examples of this is that when tourists visit the show of cultural dance of ethnic people in the northern part of Thailand which is organized especially for tourists, the show will last only about 10 minutes, while the original one lasts for two hours, meaning that only some parts of the dance have been performed for tourists due to the time limit, and this kind of dance is known as "artificial culture" (the culture that is just for show, which is not authenticity culture). Eureka Consulting Company (2012) argued that the process of adapting local culture as artificial culture makes tourist intresting as "tourist trap”. Similar to Eureka, Hunter (2011) also argued that artificial culture is not considered as a part of cultural tourism, as tourists did not learn and experience the true story and original knowledge about those cultures. Lynch, Duinker, Sheehan, and Chute (2011) also insisted that cultural tourism must be in a form that provides tourists with enough opportunities to learn and experience the uniqueness of local culture where they visit, which will be significantly different from place to place.

According to Figini and Vici (2012), Eureka Consulting Company (2012), Hunter (2011), and Lynch et al. (2011), it can be argued that cultural tourism is the form of tourism that provides wider opportunity and real-life experience for tourists. In the same vein, cultural tourism is also considered as the form of tourism that is able to generate a social awareness of conserving and protecting cultural resources. Therefore, not only tourism sector and other private sectors, but also local communities have been required to have the responsibility and coordination in order to strengthen cultural tourism itself and maximize its value for all stakeholders.

In relation to the above mentioned, the researchers are interested in investigating cultural tourism development in Chiang Rai, one of the most famous tourist destinations in Thailand, aiming to promote Chiang Rai as the destination for cultural tourism and examine tourist expectation and experience of cultural tourism in Chiang Rai. The finding will be developed as the means to maximize tourist satisfaction and minimize the gap between pre- and post-experience in cultural tourism of tourists in Chiang Rai.

\section{Literature Review}

\section{Tourist Expectation}

Vroom (1994) has described the element of expectation in the expectancy theory. According to the author, expectation consists of three elements called VIE (valence, instrumentality, and expectancy). V or valence illustrates that each person is satisfied with the outcome, and if the people feel good, it means that they will get positive experience. I or instrumentality is defined as a way that will lead to satisfaction. E or expectancy means expectations of people, and they need different expectations. They will be satisfied when their needs are met. Upon receiving the response, then a person will get the satisfaction and expectations will increase. The main factors affecting the expectations of the service offered are: (1) has been told through travel recommendations from others who have experienced the past; (2) the travel needs of an individual; (3) travel experiences in the past; (4) messages from the media and the provider; and (5) prices during peak periods.

The nature of the expectations of tourists, which helps in the decision of the individual to choose an action, may depend on the nature of the different backgrounds of the individual. Expectations of the parties may be different, because they have their own ideas and their needs are different. In tourism, expectations of tourists are expected in the tourism services on travelers' visits. The expectation is the basic service that meets 
the needs. When visitors' higher expectations of the service are met, they will be satisfied with that service. In contrast, if tourists do not get the service that they expect or if the service quality is lower than expected, they will feel offended and may not come again. According to Li, Lai, Harrill, Kline, and Wang (2011), tourists are expected towards travel due to six reasons, which consisted of patience of the staff, privacy need services, clear marketing communications, reasonable price, word of mouth, and previous experience of tourist. Expectations show the needs of people from the present to the future. The personal experience is a measure of what is happening. In a service business, especially the tourism industry, it is important to study the expectations of tourists, as this will lead us to understand more of what travelers want to make use of their experience to meet their expectations and generate high satisfaction towards all products and services provided.

\section{Tourist Experience}

Tourism experience can be in the form of direct experience from tourists' own travel and indirect experience (listening to the stories from friends, family, or relatives). In terms of tourism business as well as other related businesses, the services provided, such as tourism information, relaxation and enjoyment environment, friendly staff, and good advice, are considered as elements to satisfy tourists' needs and expectations. According to Beeho and Prentice (1997), tourists who feel that their expectations were met will advise their friends, families, and relatives to visit those places and they will also return to those places again. On the contrary, Blackwell, Minard, and Engel (2001) argued that if tourists are unhappy with the services provided or if they experienced bad things, they will not go back to those places again and they will tell those to their friends, families, and relatives. Wang, Chen, Fan, and Lu (2012) pointed out that the story or experience of tourism from friends, family members, or relatives has played a vital part in the decision-making process of people who planned to travel and insisted that most people will change their decisions after receiving or listening to the unhappy story or bad experience of friends, family members, or relatives (not to go). Quan and Wang (2004) described tourism experience as a relationship of activities and environment and mentioned that the best experience depends on the best support of related services, such as food services, accommodation, transport, and travel services. Tourists' experience might typically be different, depending on their previous experience and information they have as well as the responses to their expectations. Similarly, Chaudhary (2000) argued that tourists would be satisfied if they got what they expected and would be dissatisfied if they did not get what they expected. In relation to Quan and Wang (2004), it can be argued that the quality of tourism products and services is considered as the key element for generating satisfaction and good experience for tourists as well as meeting their expectations.

\section{Tourist Perception}

Bernstein, Penner, Clarke-Stewart, and Roy (2012) have described perception as the process that occurs after the stimulus has been interpreted as a feeling and what is meant by knowledge, experience, and understanding of a person. It is perceived as something that must be learned without learning or experience and will not cause the recognition performance. According to perception theory, it is important to learn the basic elements of the perception process of a person, because any behavioral response is based on the perception of their environment and the ability to interpret it. It can be said that learning and performance of people depend on several factors such as recognition, efficient stimulation factors which include sensory perception, and psychosocial factors (knowledge and attitude). 
There are three steps of perception. These include stimuli (products and services), perception of need, and response to the need. The factors that influence perception consist of characteristics of recipients (users) which are divided into two aspects including physical and psychological. Physical means having complete sensory perceptions, such as hearing and visioning. This quality of these factors will result in the correctness of perception. Psychological characteristics include memory, intelligence, emotion, interest, intention, value, and previous experience.

It can be considered that the perception process is a process that relates to cognitive thinking, feeling, learning, memory, and decision-making.

In terms of tourism, tourist perception can be divided into three stages including: (1) the exposure stage, when tourists receive related information; (2) the attention stage, when tourists consider and reconsider the information they received; and (3) the comprehension stage, when tourists try to interpret the information they received.

The characteristics of tourism stimuli include: (1) stimuli to generate perception which are tourist attraction, tourism season, and tourism situation; (2) visitors' senses (sense organ) that make them feel like traveling, seeing, and hearing ads or various forms of tourism promotion; (3) experience or prior knowledge of the tourist; and (4) interpretation of tourism attractions or from previous experience or knowledge of the travel experience of tourists. Tourism stimuli can promote the possibility of getting what we need and know much more in line with the experience.

\section{Cultural Tourism}

Smith (2003) has described that cultural tourism is the form of journey of a person or a group of people who are seeking for the place where they can admire the unique beauty of the culture of other people with a high respect of those cultures of each other in order to form friendship and tolerance to the culture of the community. Cultural tourists will be offered an opportunity to learn and seek for new experiences. In the areas with rich historic and cultural heritage, tourists will be told the stories of the culture which reflect and show the lifestyles of the local people in each period, festivals and traditions, as well as the stories of social or economic development in the community. The widely known cultural tourism values include conservation and preservation of cultural resources and minimization of the impact of tourism by generating the social awareness of protecting and conserving cultural resources. Cultural tourism resources mainly consist of the forms of arts and crafts, lifestyles or ways of life, language, costume, food, religions, traditions, and other cultural heritage. According to Jittangwattana (2005), cultural tourism has played a vital part in generating social awareness of cultural resources in Thailand. Goeldner and Ritchie (2009) have argued that the emphasis of cultural tourism is on educating its visitors in a different way to travel which focuses on learning and participation in the life of the community, while the mass tourism primarily focuses on the enjoyment of tourists. According to Goeldner and Ritchie (2009), it can be argued that cultural tourism allows visitors to learn in depth the differences of culture and language, costume, and ways of life which enable them to get novel experience that they expected before their travel.

From all concepts, the researchers created a questionnaire about the expectations of the tourism experience and the experience gained in the field of tourism travelers. They are arts and crafts, Lanna Lifestyle (Northern Thailand style), lifestyles, food, festivals, indigenous people, and cultural heritage. 


\section{Methodology}

\section{Sample and Mean for Data Collection}

Questionnaires were used as the means of data collection in this study. The questionnaire was in the form of a 5-point Likert scale (ranging from 1 to 5) and was created based on theoretical concepts and the aim of the study. The questionnaire has been divided into three parts. The first part consists of general questions about tourists. The second part consists of the questions towards tourists' expectations and their experience of traveling in Chiang Rai towards six key aspects which include: (1) arts and crafts; (2) ways of life of local people; (3) food; (4) events and festivals; (5) ethnic/indigenous people; and (6) cultural heritage. These items were created and modified from previous studies of G. Lee and C. Lee (2009), Wang et al. (2012), Beeho and Prentice (1997), Li et al. (2011), and Figini and Vici (2012). There are five levels of each factor: expectation and experience. For the expectation, 5 is for highly expected, 4 is for expected, 3 is for somehow expected, 2 is for less expected, and 1 is for unexpected. For the experience, 5 is for highly experienced, 4 is for experienced, 3 is for somehow experienced, 2 is for less experienced, and 1 is for inexperienced.

The last part consists of open-ended questions asking towards what tourists considered as the strength and weakness of cultural tourism management in Chiang Rai and how to improve and develop a better quality.

The questionnaire has been tried out with 40 foreign tourists in order to ensure the reliability. The edited and completed version of questionnaire has been completed, using accidental sampling, by 400 foreign tourists who visited Chiang Rai and were waiting for the departure flight at the Mae Fah Luang Chiang Rai International Airport.

\section{Data Analysis}

In the stage of data analysis, the One-way ANOVA has been used as the tool for gap analysis between the expectation and the experience of tourists. A general profile of tourists has been illustrated by descriptive statistics.

\section{Results}

\section{Tourists’ Demographic Profile of Respondents}

As illustrated in Table 1, it is found that the majority of foreign tourists are female. In terms of gender, 244 of the tourists are female (61\%) and 156 are male (39\%), and more than $42 \%$ are married. In terms of age, more than one third of the respondents are at the age of 20-29. In terms of marital status, the highest percentage is $41.8 \%$ (married). In terms of purpose of visit, leisure is the main purpose as the number shows more than 88.6\%. In terms of source of information, internet is the biggest source of information about Chiang Rai while friends and relatives is the second powerful source. In terms of country of origin, France, Australia, and Germany were among the major groups of tourists, whose percentages are $22.8 \%, 11.5 \%$, and $10.6 \%$ respectively.

Table 1

General Profile of Tourists

\begin{tabular}{llll}
\hline Factor & & No. & Percentage (\%) \\
\hline \multirow{2}{*}{ Gender } & Male & 156 & 39.0 \\
& Female & 244 & 61.0 \\
\hline
\end{tabular}


(Table 1 continued)

\begin{tabular}{|c|c|c|c|}
\hline Factor & & No. & Percentage (\%) \\
\hline \multirow{6}{*}{ Age } & Lower than 20 & 26 & 6.5 \\
\hline & $20-29$ & 125 & 31.2 \\
\hline & $30-39$ & 100 & 25.0 \\
\hline & $40-49$ & 80 & 20.0 \\
\hline & $50-59$ & 34 & 8.5 \\
\hline & Above 60 & 35 & 8.8 \\
\hline \multirow{4}{*}{ Marital status } & Single & 156 & 39.0 \\
\hline & Married & 167 & 41.8 \\
\hline & Divorce/widowed & 25 & 6.2 \\
\hline & Not married but live together & 52 & 13.0 \\
\hline \multirow{3}{*}{ Purpose of visit } & Leisure travel & 354 & 88.6 \\
\hline & Business travel & 21 & 5.2 \\
\hline & Visit friends and relatives & 25 & 6.2 \\
\hline \multirow{8}{*}{$\begin{array}{l}\text { Sources of infomation } \\
\text { about Chiang Rai }\end{array}$} & Newspapers & 5 & 1.2 \\
\hline & Travel agents/tour operators & 71 & 17.8 \\
\hline & Travel offices abroad & 10 & 2.5 \\
\hline & Friends and relatives & 125 & 31.2 \\
\hline & Books & 46 & 11.5 \\
\hline & Internet/websites & 127 & 31.8 \\
\hline & TV/radio & 0 & 0 \\
\hline & Guides & 16 & 4.0 \\
\hline \multirow{19}{*}{ Country of origin } & France & 91 & 22.8 \\
\hline & Australia & 46 & 11.5 \\
\hline & Germany & 42 & 10.6 \\
\hline & Austria & 26 & 6.5 \\
\hline & China & 26 & 6.5 \\
\hline & United States of Amercia (USA) & 21 & 5.2 \\
\hline & Italy & 21 & 5.2 \\
\hline & Canada & 20 & 5.0 \\
\hline & Japan & 20 & 5.0 \\
\hline & England & 11 & 2.8 \\
\hline & The Netherlands & 11 & 2.8 \\
\hline & Singapore & 10 & 2.5 \\
\hline & United Kingdom (UK) & 10 & 2.5 \\
\hline & Belgium & 10 & 2.5 \\
\hline & Malaysia & 10 & 2.5 \\
\hline & Korea & 10 & 2.5 \\
\hline & Indonesia & 5 & 1.2 \\
\hline & Spain & 5 & 1.2 \\
\hline & Switzerland & 5 & 1.2 \\
\hline
\end{tabular}

Importance-Performance Analysis in Tourist Expectation and Tourist Experience in Cultural Tourism

The research results explain that arts and crafts was the cultural aspect with a high expectation of tourists but tourists experienced lower than they expected (moderate/somehow experienced or do not meet the expectation).

Ways of life is the only cultural aspect with a high expectation and tourists are highly experienced (meet the expectation) and tourist experience as well. 
The other four cultural aspects, local food, festivals, indigenous people and culture, and cultural heritage were among the aspects which mixed the level of expectation and level of experience gained.

Interesting findings in the case of indigenous people and culture are shown in Table 2. Tourists mentioned that having more opportunity to witness or experience the unique life of ethnic people or family will be the key factor attracting them to visit. Figure 1 will also show the comparison of tourist expectation and tourist experience.

Table 2

Tourist Expectation and Tourism Experience in Cultural Tourism

\begin{tabular}{|c|c|c|c|c|c|c|c|}
\hline \multirow{2}{*}{ Title } & \multirow{2}{*}{ Element of cultural tourism } & \multicolumn{2}{|c|}{ Expectation } & \multirow{2}{*}{$\begin{array}{l}\text { Expectation } \\
\text { level }\end{array}$} & \multicolumn{2}{|c|}{ Experience } & \multirow{2}{*}{$\begin{array}{l}\text { Experience } \\
\text { level }\end{array}$} \\
\hline & & Mean & S.D. & & Mean & S.D. & \\
\hline \multirow{4}{*}{$\begin{array}{l}\text { Arts and } \\
\text { crafts }\end{array}$} & Variety of arts and crafts & 3.65 & 0.81 & $\mathrm{HE}$ & 3.17 & 0.81 & SP \\
\hline & Uniqueness of arts and crafts & 3.58 & 0.69 & $\mathrm{HE}$ & 3.36 & 0.77 & SP \\
\hline & Quality of local crafts and handworks & 3.57 & 0.78 & $\mathrm{HE}$ & 3.35 & 0.83 & SP \\
\hline & Local arts and craft workshops & 3.45 & 0.87 & HE & 3.30 & 0.86 & SP \\
\hline \multirow{4}{*}{$\begin{array}{l}\text { Lanna } \\
\text { Lifestyle } \\
\text { (Northern } \\
\text { Thailand } \\
\text { style) }\end{array}$} & A small town and villages in rural countryside & 3.62 & 0.86 & $\mathrm{HE}$ & 3.47 & 0.93 & HP \\
\hline & $\begin{array}{l}\text { Opportunity to see or experience local people } \\
\text { through activities }\end{array}$ & 3.53 & 0.87 & $\mathrm{HE}$ & 3.45 & 0.85 & HP \\
\hline & Hospitality destinations & 3.61 & 0.94 & $\mathrm{HE}$ & 3.61 & 0.90 & HP \\
\hline & Happy for Northern styles & 3.67 & 1.03 & $\mathrm{HE}$ & 3.69 & 0.87 & HP \\
\hline \multirow{4}{*}{ Local food } & Local and traditional cuisines & 3.65 & 0.94 & $\mathrm{HE}$ & 3.58 & 0.82 & HP \\
\hline & Uniqueness of healthy food & 3.48 & 0.97 & $\mathrm{HE}$ & 3.39 & 0.97 & SP \\
\hline & Good ingredients & 3.60 & 0.87 & $\mathrm{HE}$ & 3.52 & 0.82 & HP \\
\hline & Quality of food/cleanliness/safety food & 3.52 & 0.93 & $\mathrm{HE}$ & 3.61 & 0.91 & HP \\
\hline \multirow{3}{*}{ Festivals } & Variety of festivals & 2.85 & 1.14 & SE & 2.91 & 1.09 & SP \\
\hline & Uniqueness of festivals & 2.86 & 1.15 & SE & 2.73 & 1.06 & SP \\
\hline & Quality of festivals & 2.85 & 1.15 & SE & 2.87 & 1.11 & SP \\
\hline \multirow{2}{*}{$\begin{array}{l}\text { Indigenous } \\
\text { people }\end{array}$} & $\begin{array}{l}\text { Opportunity to see or experience unique or } \\
\text { different indigenous people }\end{array}$ & 3.52 & 0.96 & $\mathrm{HE}$ & 3.44 & 1.00 & HP \\
\hline & $\begin{array}{l}\text { Cross cultural learning from indigenous } \\
\text { people's lifestyles }\end{array}$ & 3.39 & 1.10 & $\mathrm{SE}$ & 3.30 & 1.07 & SP \\
\hline \multirow{3}{*}{$\begin{array}{l}\text { Cultural } \\
\text { heritage }\end{array}$} & Richness of cultural heritage & 3.51 & 0.87 & $\mathrm{HE}$ & 3.45 & 0.91 & HP \\
\hline & Uniqueness of cultural heritage & 3.56 & 1.01 & $\mathrm{HE}$ & 3.60 & 0.92 & HP \\
\hline & Education/cultural heritage learning & 3.35 & 1.06 & SE & 3.38 & 0.98 & SP \\
\hline
\end{tabular}

Notes. Tourist expectation: $\mathrm{HE}=$ Highly expected, $\mathrm{SE}=$ Somehow expected. Tourist experience: $\mathrm{HP}=$ Highly experienced, $\mathrm{SP}=$ Somehow experienced.

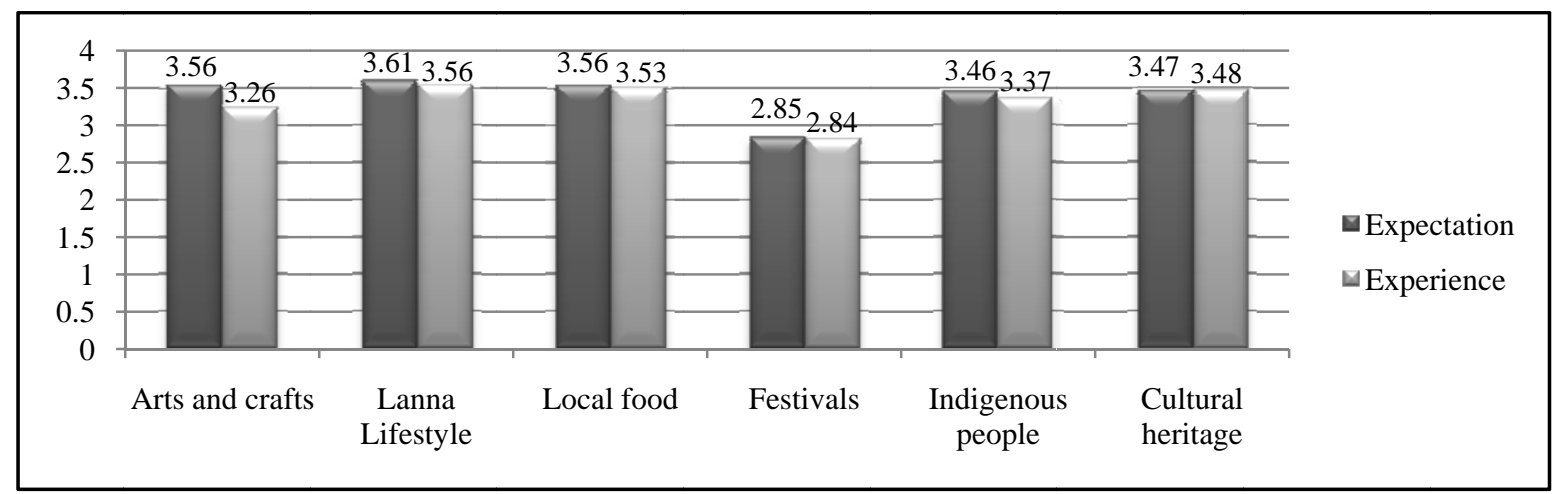

Figure 1. Comparison of tourist expectation with tourist experience. 


\section{Discussion and Conclusions}

According to the finding, the strengths of Chiang Rai as a cultural tourism destination include the rich variety of cultural resources, especially ways of life of local people and ethnic/indigenous culture. The weakness of Chiang Rai tourism is the foreign language ability of local people and tourism also needs to improve by good management of, e.g., tourist services and tourist supports, for instance, printed documents, brochures, maps, and signs particular in the place, which must be precise, clear, and in proper quantity and quality.

In terms of management of cultural tourism in Chiang Rai, cultural route, calendar of cultural activities, and continuity of promotion are needed. Also important is that good coordination, participation, and involvement of all stakeholders should also be considered as the key elements of cultural tourism management to meet tourist expectations.

As addressed in previous parts, the primary aim of cultural tourism is to generate the awareness of conserving and preserving the value of cultural resources and minimizing the impact of tourism. This is because cultural tourism is considered as the form of tourism that consumes fewer resources compared with mass tourism. This might sound strange for some tourists or even community members and travel companies as in terms of tourists, cultural tourism is the form of tourism that will create and offer them an opportunity to experience and study the very unique aspect of culture within the community where they visit, for instance, it could be considered as a potential harm to cultural resources. However, it can be argued that, according to the findings of this study, generating and proposing the appropriate approach for cultural tourism management and development in order to apply for maximizing the greatest value for community and providing benefit through the expectation of tourists can be seen as a way to promote cultural tourism in Chiang Rai.

\section{Limitation and Recommendation for Future Study}

In terms of future study, the study of the appropriate approach for cultural tourism development in Chiang Rai is one of the most interesting issues. In relation to research method, the use of only the quantitative research method is a limitation for obtaining in-depth information and details. As a result, for future study, the qualitative research method, such as an in-depth interview with key informants, should be applied, as this method will help the researchers to access more in-depth details.

\section{References}

Beeho, A. J., \& Prentice, R. C. (1997). Conceptualizing the experiences of heritage tourists: A case study of New Lanark world heritage village. Tourism Management, 18(2), 75-87.

Bernstein, D. A., Penner, L. A., Clarke-Stewart, A., \& Roy, E. J. (2012). Phychology (9th ed.). Belmont: Wadsworth Cengage Learning.

Blackwell, D., Minard, W., \& Engel, F. (2001). Customer behavior. Orlando: The Dryden Press.

Chaudhary, M. (2000). India's image as a tourist destination: A perspective of foreign tourists. Tourism Management, 21(3), 293-297.

Eureka Consulting Company. (2012). Projects studies in tourism: An image of the country from foreigners. Bangkok: Tourism Authority of Thailand.

Figini, P., \& Vici, L. (2012). Off-season tourists and the cultural offer of a mass-tourism destination: The case of Rimini. Tourism Management, 32(4), 825-839.

Goeldner, C., \& Ritchie, B. (2009). Tourism: Principles, practices, and philosophies. New York, N.Y.: John Wiley \& Sons. 
Hunter, W. (2011). Rukai indigenous tourism: Representations, cultural identity, and Q method. Tourism Management, 32(2), 335-348.

Jittangwattana, B. (2005). Sustainable tourism development. Bangkok: Press \& Design.

Lee, G., \& Lee, C. (2009). Cross-cultural comparison of the image of Guam perceived by Korean and Japanese leisure travelers: Importance-performance analysis. Tourism Management, 30(6), 922-931.

Li, X., Lai, C., Harrill, R., Kline, R., \& Wang, L. (2011). When east meets west: An exploratory on study on Chinese outbound tourists' travel expectations. Tourism Management, 32(4), 741-749.

Lynch, M., Duinker, N. P., Sheehan, R. L., \& Chute, E. J. (2011). The demand for Mi'kmaw cultural tourism: Tourism perspectives. Tourism Management, 32(5), 977-986.

Quan, S., \& Wang, N. (2004). Towards a structural model of the tourist experience: An illustration from food experiences in tourism. Tourism Management, 25(3), 297-305.

Smith, M. K. (2003). Issue in cultural tourism studies. London: Routledge.

Vroom, H. V. (1994). Work and motivation. San Francisco: Jossey Bass.

Wang, W., Chen, S. J., Fan, L., \& Lu, J. (2012). Tourist experience and wetland parks: A case of Zhejiang, China. Annals of Tourism Research, 39(4), 1763-1778. 